\title{
Treatment of Storm Water from Agricultural Catchment in Pilot Scale Constructed Wetland
}

\author{
Linda GRINBERGA ${ }^{1 *}$, Didzis LAUVA ${ }^{2}$, Ainis LAGZDINS ${ }^{3}$ \\ ${ }^{1,3}$ Department of Environmental Engineering and Water Management, Latvia University of Life Sciences and \\ Technologies, Akademijas iela 19, Jelgava, LV-3001, Latvia \\ ${ }^{2}$ Department of Physics, Riga Stradins University, Dzirciema iela 16, Riga, LV-1007, Latvia
}

\begin{abstract}
Constructed wetlands as a treatment system are widely explored in different climate conditions and established to be effective in pollution removal from water environment. This study aims to demonstrate the performance of pilot-scale subsurface flow constructed wetland for storm water treatment in Latvia. The catchment basin was located in a farmyard of agricultural area and storm water was collected from the impermeable pavements. Storm water was accumulated in an open pond and periodically pumped above the filter part of the subsurface flow constructed wetland. Grab samples were collected once or twice per month at the inlet and outlet of the treatment system during a period of 73 months from year 2014 to 2020 . Water quality parameters as nitrate nitrogen $\left(\mathrm{NO}_{3}-\mathrm{N}\right)$, ammonium nitrogen $\left(\mathrm{NH}_{4}-\mathrm{N}\right)$, total nitrogen (TN), orthophosphate phosphorus ( $\left.\mathrm{PO}_{4}-\mathrm{P}\right)$, and total phosphorus (TP), total suspended solids (TSS), biochemical oxygen demand (BOD5) and chemical oxygen demand (COD) were monitored. Water level at the inlet structure was automatically measured and flow rate was calculated based on the Manning equation for partially filled circular pipes. Results showed the reduction of average concentrations for all parameters during the study period. However, in some sampling cases concentrations increased at the outlet of the treatment system and can be explained by influencing factors of farming and maintenance. The treatment efficiency of $\mathrm{NO}_{3}-\mathrm{N}, \mathrm{NH}_{4}-\mathrm{N}$, TN, PO4-P, TP, TSS, BOD5 and COD concentrations was $17 \%, 68 \%, 55 \%, 78 \%, 80 \%, 57 \%, 80 \%$ and $74 \%$, respectively. The study site demonstrated a potential to improve water quality in the long term.
\end{abstract}

Keywords - Constructed wetland; nutrients; removal; subsurface flow

\section{INTRODUCTION}

The idea of constructed wetland as a treatment system was firstly defined in 1950s by Dr. Käthe Seidel in Germany [1]. Currently constructed wetlands in various technological combinations are implemented and studied to improve water quality from various sources and decrease pollution impact on the environment in different climate and maintenance conditions. Constructed wetlands can be adapted to a wide range of pollutants meaning the amount and concentration due to complex mechanical, biological and chemical processes in a wetland bed. This method based on natural actions is suggested as an individual or a complementary system for treatment of domestic wastewater, industrial and agricultural wastewater and storm water in urban areas [2]. Storm water content is usually specific in different cities [3] and depends on climate and surface conditions, population density, industrial objects and other urban factors. Guidelines and best practices for urban storm water treatment in constructed wetlands are available in many countries [4]. This study focuses on storm water treatment from the impermeable surfaces in

\footnotetext{
*Corresponding author.

E-mail address: linda.grinberga@llu.lv 
agricultural areas. Surface runoff from hard pavements can be polluted with high amounts of organic matter. Monitoring data obtained in this study site showed the similar inflow concentrations to domestic wastewater comparing the $\mathrm{BOD}_{5}, \mathrm{COD}$ and nutrients. Decreasing of BOD and COD concentrations [1], [5]-[9] in municipal wastewater using constructed wetlands is widely studied over the countries. The treatment method in subsurface flow constructed wetland for storm water from agricultural areas in this article was studied. Constructed wetlands have additional benefits as increasing biological diversity, storage of the water resource, and recreational possibilities [10]. Constructed wetland can be designed with less electricity consumption during exploitation and with low maintenance as a treatment system [11].

\section{Materials ANd Methodology}

\subsection{Study Site}

The research object was located in a middle part of Latvia, Jelgava region, in the nitrate vulnerable zone made in accordance with the criteria set out in the EU Nitrates Directive [12]. The catchment area of 0.81 ha serves to periodically store agricultural equipment and solid manure. Greenhouses, biogas power plants and animal farmhouses are located in a catchment basin. Storm water in similar farmyards can contain the number of suspended solids, organic matter, oils and dust leached from roofs and other surfaces. Storm water from roofs and hard surfaces within the catchment area was collected in surface runoff capturing wells and delivered through the subsurface piping system to the final part of the storm water drainage system along the no-pressure pipeline system. The treatment system for the collected storm water begins with the storage basin in the study site. Storm water was released to the treatment system by the covered pipe DN $300 \mathrm{~mm}$ from the drainage system.

The storm water treatment system was designed in two levels. In the first level the mechanical treatment was realized. The storage basin as shown in Fig. 1 is made as an open pond and is hydro isolated from the groundwater and it serves as a sedimentation pond and temporarily stores water during the heavy storm events by absorbing the peak flows. The primary sedimentation was observed in this initial part of the treatment system.

Water is automatically pumped to the second stage of the treatment system when water level exceeds the depth of $1.2 \mathrm{~m}$ in a storage basin. The biological treatment in horizontal subsurface flow constructed wetland is practised as shown in Fig. 1. The filter part of the constructed wetland is filled with coarse sand and gravel in proper layers with a total depth of $0.9 \mathrm{~m}$. The filter is hydro isolated from the groundwater and planted with common reed from above.

Storage basin

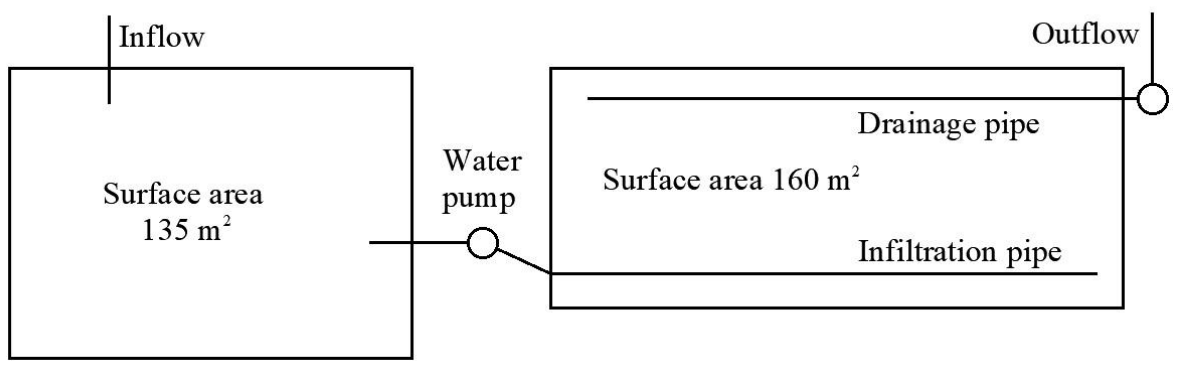

Fig. 1. Schematic drawing of the storm water treatment system at the Mezaciruli farm. 


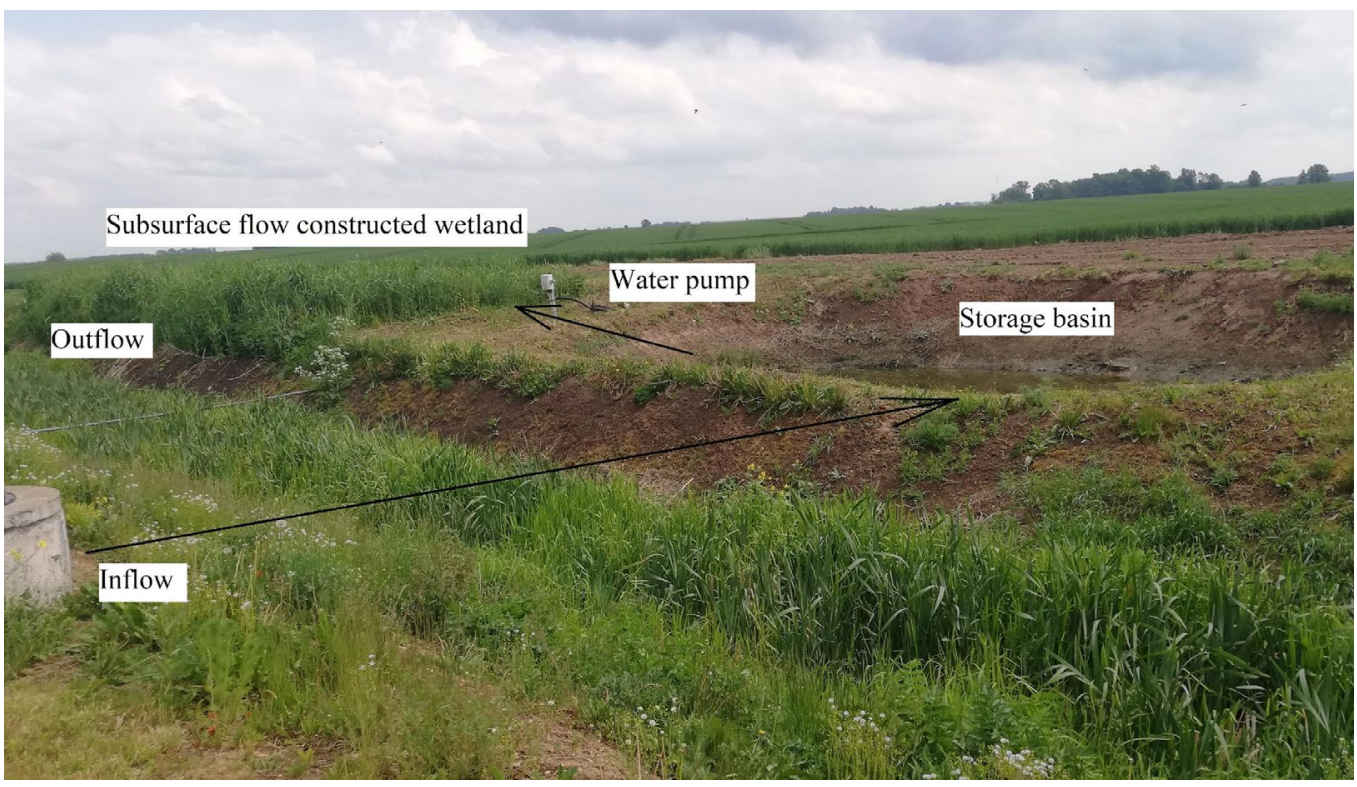

Fig. 2. A storm water treatment system with horizontal subsurface slow constructed wetland at the Mezaciruli farm. Photograph taken by the author.

The landscape of the treatment plant is demonstrated in Fig. 2. The object gives an opportunity to detect any difficulties of maintenance and to see the impact of occasional events on the treatment efficiency, as the study site is located on a real farm.

\subsection{Sampling and Water Quality Analysis}

Water samples were collected in plastic bottles previously washed and rinsed with distilled water using a grab sampling approach at the inflow and at the outflow of the storm water treatment system with subsurface flow constructed wetland, once or twice per month depending on water discharge. The monitoring period for this study was 73 calendar months during the period from August, 2014 to December, 2020. Water samples were analysed for concentrations $\left(\mathrm{mg} \mathrm{L}^{-1}\right)$ of water quality parameters as nitrate nitrogen $\left(\mathrm{NO}_{3}-\mathrm{N}\right)$, ammonium nitrogen $\left(\mathrm{NH}_{4}-\mathrm{N}\right)$, total nitrogen $(\mathrm{TN})$, orthophosphate phosphorus $\left(\mathrm{PO}_{4}-\mathrm{P}\right)$, and total phosphorus (TP) and as total suspended solids (TSS) according to the Latvian Standards at the Hydrochemistry Laboratory of Latvian Institute of Aquatic Ecology. Water samples for the period of 12 months were additionally analysed for concentrations $\left(\mathrm{mg} \mathrm{L}^{-1}\right)$ of biochemical oxygen demand in five days $\left(\mathrm{BOD}_{5}\right)$ and chemical oxygen demand (COD) according to the Latvian Standards at the Institute of Food Safety, Animal Health and Environment BIOR.

Retention efficiency of the treatment system with constructed wetland by the following equation was calculated to estimate the removal percentage for the monitored parameters.

$$
\text { Retention }=\frac{(C i-C o)}{C i} \cdot 100(\%),
$$

where $C i$ and $C o$ are the concentrations of the monitored parameters at the inflow and outflow, respectively.

Considering the performance efficiency of the pilot-scale constructed wetland in Latvia, water quality data were collected. Water quality parameters can be grouped in two parts, parameters 
that are monitored in agricultural areas as nutrient concentrations and parameters that are analysed to describe the content of organic matter in wastewater as oxygen demand. As the storm water was gathered in agricultural areas, nutrient concentrations were monitored according to regulations in Latvia and nitrate directive [12]. The biochemical and chemical oxygen demand and total suspended solids were monitored to measure the biodegradable organic matter in the water [13]. Boxplot figures are used to display the range of domain concentrations of measured nutrients. Statistical analysis was performed at $95 \%$ confidence level. The sample dataset was divided in categories accordingly to analysed parameters. The $p$-value for the Kolmogorov-Smirnov test statistic for the assessment of normality was used. A $p$-value $\geq 0.05$ indicated failure to reject the hypothesis that normality in data distribution was assumed. When normality was assumed, Paired $t$-Test was used to determine the statistical significance of the particular dataset. When normality could not be assumed, Wilcoxon Signed-Rank Test was used. Similar statistical approach can be also found in literature [14], [15].

The catchment basin of the subsurface flow constructed wetland in the study site was located in the farmyard and covered with impermeable surface pavement in a form of concrete slabs.

The described area with mentioned surface conditions and existing drainage system can be considered as a rain water sewerage system according to the legal acts of the Republic of Latvia. Storm water amount estimation from the catchment basin initially was made according to the intensity calculation method provided in Latvian Construction Standard LBN 223-15 'Sewerage constructions' (available in Latvian). Monitoring data for precipitation were obtained from the nearest meteorological station in Dobele city. Water level at the inlet structure was measured using Mini-Diver water level data loggers. Flow rate was calculated based on the Manning equation [16] for partially filled circular pipes during the period of monitoring.

\section{RESUltS AND DisCUSSION}

The efficiency of the storm water treatment plant with the horizontal subsurface flow constructed wetland can be evaluated by retention, \%, if the concentrations of water quality indicators are compared at the inlet and outlet of the system. Furthermore, the treatment quality of the system has to be assessed by the dynamic changes of flowrate and incoming water quality. Monitoring data of water amount at the inflow are demonstrated in Fig. 3 and compared with precipitation data. The direct correlation between precipitation and flow rate was not observed which can be explained by postponed water flow through the drainage system due to absorption, infiltration losses through leaky system and evaporation. Flow rate data in Fig. 3 however show flowrate peak episodes after heavy storm events.

The pattern of quantitative data of nutrient concentrations in collected water samples at the inlet and outlet of the treatment system with constructed wetland is demonstrated by boxplots for $\mathrm{NO}_{3}-\mathrm{N}$, $\mathrm{NH}_{4}-\mathrm{N}$ and TN in Fig. 4 and for $\mathrm{PO}_{4}-\mathrm{P}$ and TP in Fig. 5. Data is not symmetric, there are many outliers which can occur in an active farm and uncontrolled impacting factors. Medians for all displayed nutrients at the outflow are under the medians at the inflow and for $\mathrm{NO}_{3}-\mathrm{N}$ and $\mathrm{TN}$ the range values at the outflow are under the range values at the inflow. Fig. 4 proves the potential of the constructed wetland to reduce the concentrations of the nitrogen compounds. A strong logarithmic relationship between retention, $\%$ and inflow concentrations, $\mathrm{mg} \mathrm{L}^{-1}$ for $\mathrm{TN}$ with a determination coefficient of 0.69 was detected. 


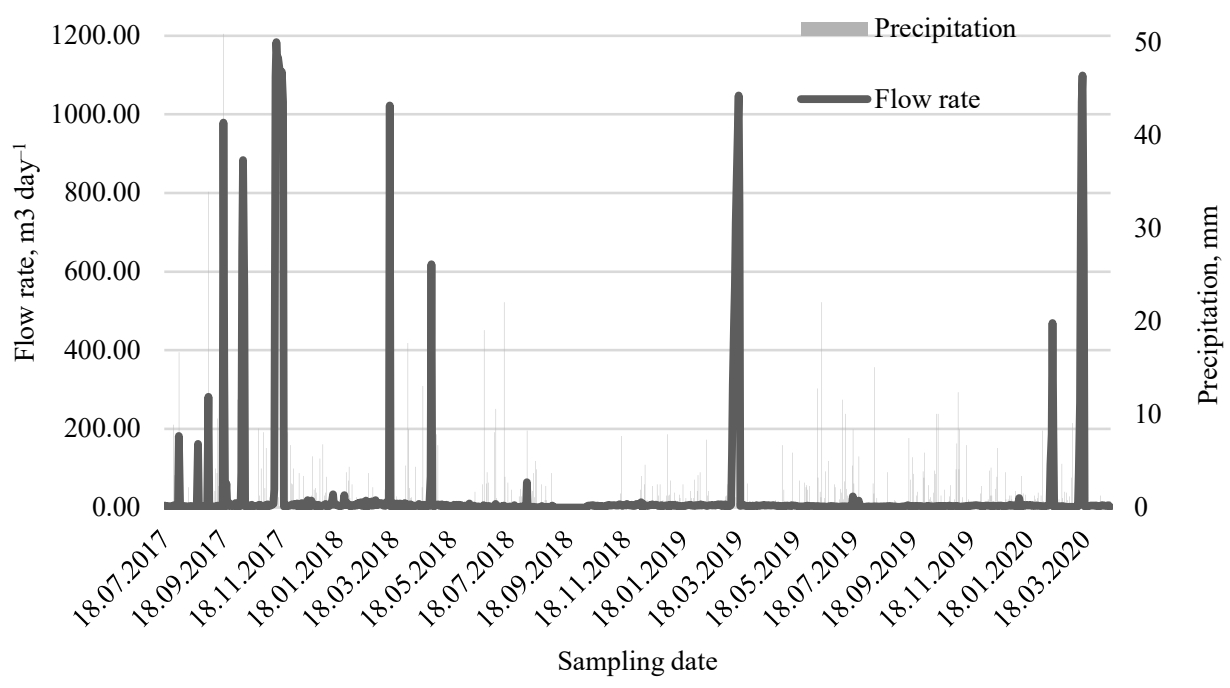

Fig. 3. Flow rate, $\mathrm{m}^{-3} \mathrm{day}^{-1}$ from the catchment basin of farm Mezaciruli, monitored from August 2014 to December 2020 and daily precipitation, $\mathrm{mm}$.

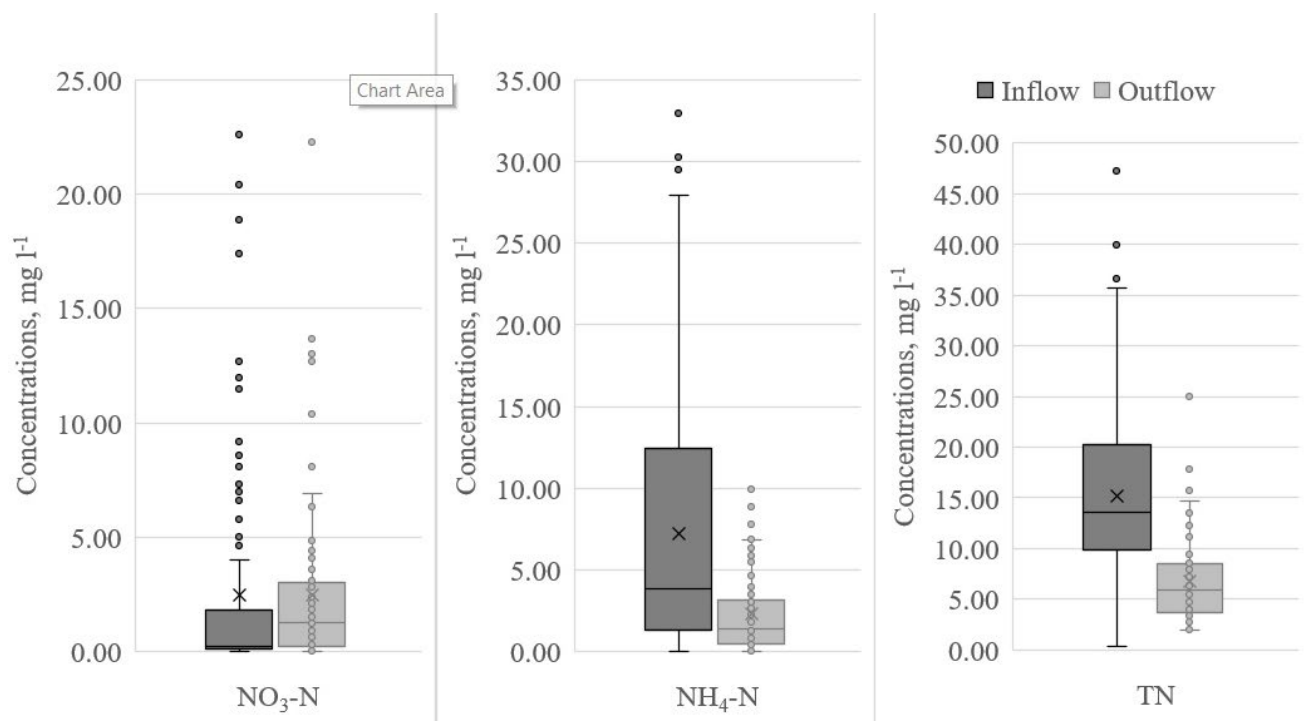

Fig. 4. Box plots for $\mathrm{NO}_{3}-\mathrm{N}, \mathrm{NH}_{4}-\mathrm{N}$ and $\mathrm{TN}$ at the inflow and outflow of the treatment system. 

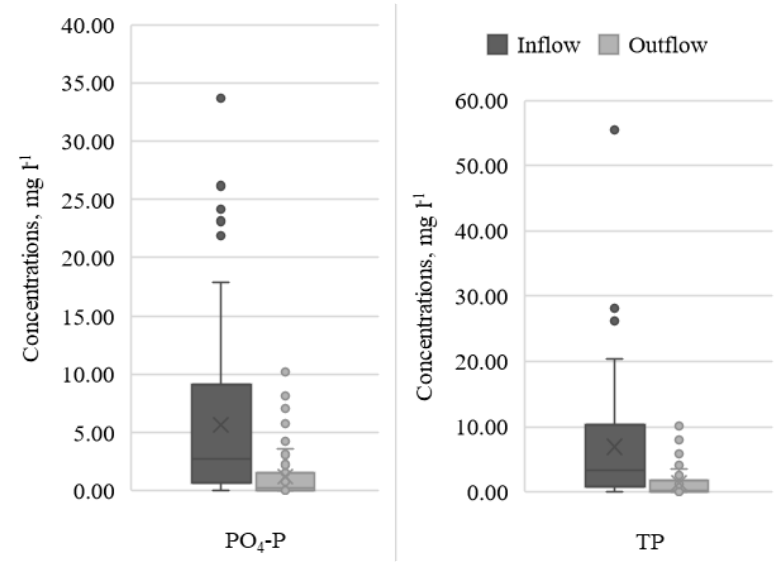

Fig. 5. Box plots for $\mathrm{PO}_{4}-\mathrm{P}$ and TP at the inflow and outflow of the treatment system.

For $\mathrm{PO}_{4}-\mathrm{P}$ and TP concentrations the retention indicates high percentage when overall ratio between inlet and outlet concentrations is compared, $78 \%$ and $80 \%$, respectively. Boxplots in Fig. 5 indicates again a low symmetry of data set and the second quartile of the outflow is located slightly under the second quartile at the inflow. The interquartile ranges are reasonably different for inflow and outflow as shown by length of the boxes though the overall range of the data set is greater for the inflow concentrations. We can consider that $\mathrm{PO}_{4}-\mathrm{P}$ and $\mathrm{TP}$ concentrations were reduced during the treatment process. The filter material for more optimal $\mathrm{P}$ sorption could be integrated in the constructed wetland with a purpose to improve the removal efficiency of phosphorous compounds in the wetland [17]. A weak relationship between retention, $\%$ and inflow concentrations, $\mathrm{mg} \mathrm{L}^{-1}$ for TP was detected.

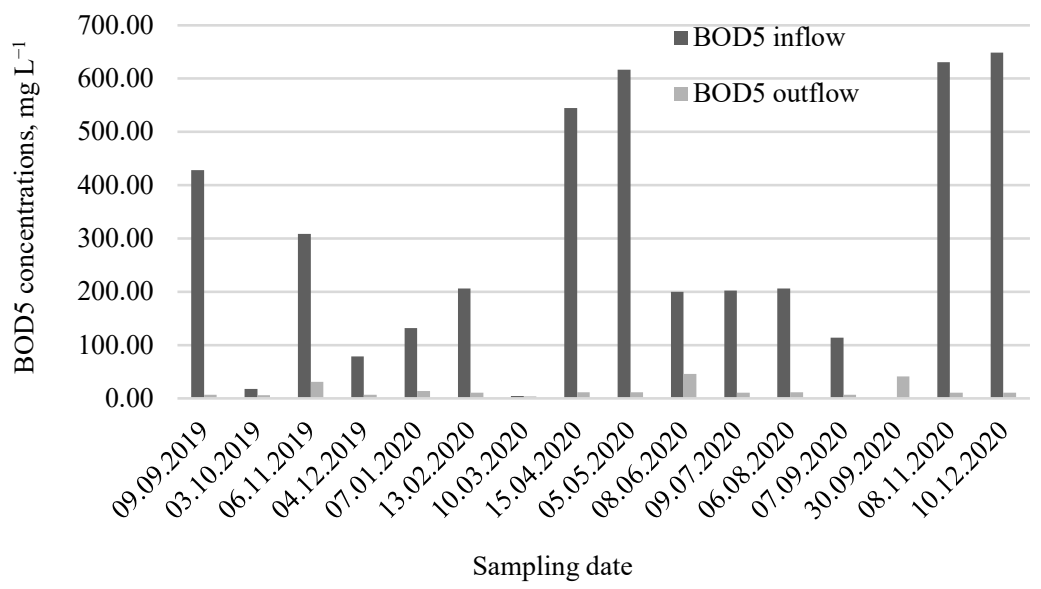

(a) 


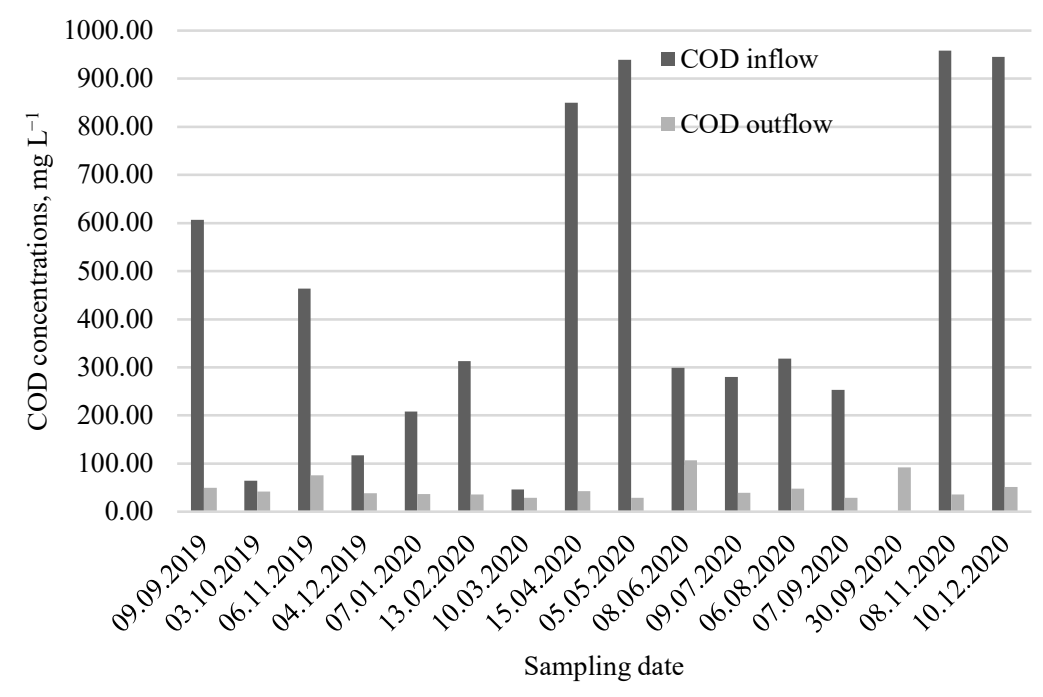

(b)

Fig. 6. The concentrations $\left(\mathrm{mg} \mathrm{L}^{-1}\right)$ of a) $\mathrm{BOD}_{5}$ and b) $\mathrm{COD}$ at the inflow and outflow of the storm water treatment system with subsurface flow constructed wetland.

The concentrations by the sampling date at the inflow and outflow is demonstrated at Fig. 6 . The retention efficiency of $\mathrm{BOD}_{5}$ and $\mathrm{COD}$ of the storm water treatment system with subsurface flow constructed wetland was calculated by comparing the concentrations observed monthly at the inlet and outlet of the treatment system (shown in Fig. 7). The average efficiency during the study period of 12 months for $\mathrm{BOD}_{5}$ and COD was monitored $80 \%$ and $74 \%$, respectively. Monitoring data shows the average $\mathrm{BOD}_{5}$ and $\mathrm{COD}$ concentrations $273.36 \mathrm{mg} \mathrm{L}^{-1}$ and $421.94 \mathrm{mg} \mathrm{L}^{-1}$, respectively, at the inflow. Basing on the FAO levels of the major constituents of strong, medium and weak domestic wastewaters, the collected storm water in the study site can be classified as between strong ( $300 \mathrm{mg} \mathrm{L}^{-1}$ of BOD) and medium (200 $\mathrm{mg} \mathrm{L}^{-1}$ of BOD) [18]. The treatment system demonstrated a settled decrease in $\mathrm{BOD}_{5}$ and COD concentrations in all sampling cases as shown in Fig. 6.

The lowest treatment efficiency of $17 \%$ and $38 \%$ for $\mathrm{BOD}_{5}$ and COD, respectively, was observed in a sampling case in March, 2020 and in the same case there the lowest inflow concentrations for $\mathrm{BOD}_{5}$ and $\mathrm{COD}$ by 4.2 and $46.5 \mathrm{mg} \mathrm{L}^{-1}$, respectively, were monitored. Similar case with relatively low inflow concentrations and treatment efficiency was detected in a sampling case of October, 2019. These spring and autumn dates are related to periods with potentially higher precipitation. It leads to the conclusion that the water amount in a system in a form of high flow rates causes low $\mathrm{BOD}_{5}$ and $\mathrm{COD}$ concentrations at the inflow. To study if low concentrations at the inflow correlate with the retention Fig. 8 is provided. 


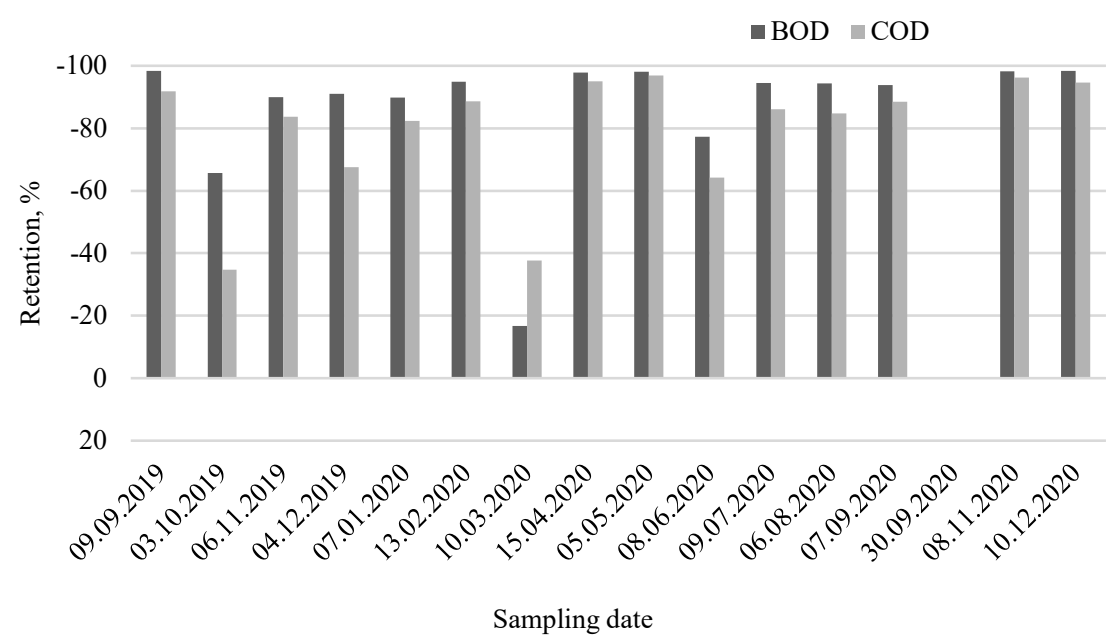

Fig. 7. The retention $(\%)$ of $\mathrm{BOD}_{5}$ and $\mathrm{COD}$ of the storm water treatment system with subsurface flow constructed wetland.

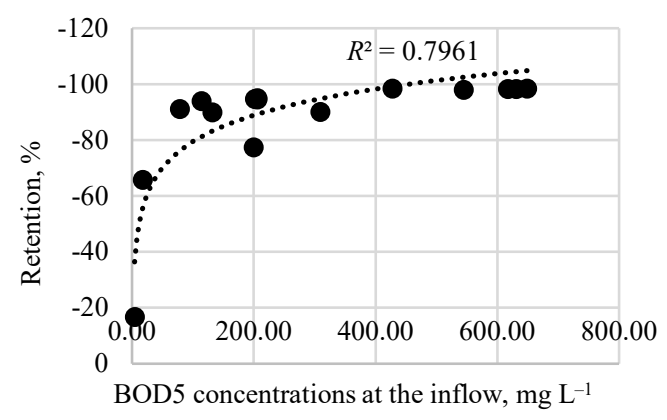

(a)

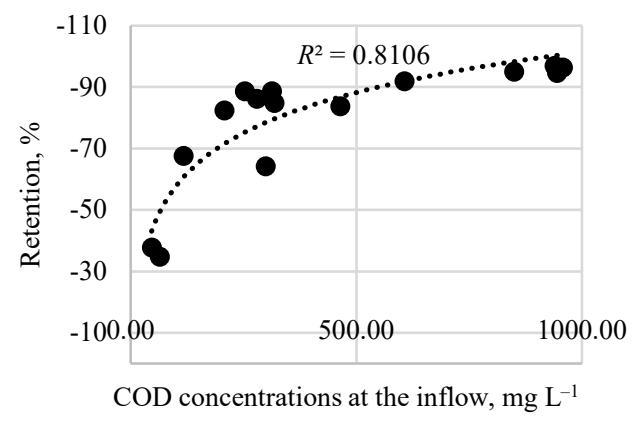

(b)

Fig. 8. The correlation between a) retention $\%$ and $b$ ) inflow concentrations, $\mathrm{mg} \mathrm{L}^{-1}$ for $\mathrm{BOD}_{5}$ and COD.

Fig. 8 demonstrates a strong logarithmic relationship between retention, \% and inflow concentrations, $\mathrm{mg} \mathrm{L}^{-1}$ for $\mathrm{BOD}_{5}$ and $\mathrm{COD}$. This leads to the conclusion that the inflow concentrations determine the retention efficiency of the constructed wetland and the reduction percentage by itself should not be used alone to evaluate the performance of the treatment system.

A hydraulic retention time in the subsurface flow constructed wetland is an important treatment influencing factor mentioned in different similar research [19]. In this research object the water flow through the filter and accordingly hydraulic retention time is related to precipitation and water moves faster during the storm events. That could be one of the influencing factors of treatment efficiency in the current research.

The Kolmogorov-Smirnov test showed that the both datasets for total nitrogen (inflow and outflow) were having a normality with $p=0.38$ and $p=0.16$ accordingly. The normality for rest of the parameter datasets was having $p \ll 0.05$. The paired t-test for total nitrogen dataset was used and the results showed significantly large difference $(p \ll 0.05)$ between inflow and outflow 
total nitrogen concentrations despite inflow dataset had $\sim 2.2$ times higher arithmetical mean value and roughly 5 times higher variance $(15.21 \pm 81.37 \mathrm{mg} / \mathrm{L}$ and $6.81 \pm 16.36 \mathrm{mg} / \mathrm{L}$, accordingly).

The Wilcoxon Signed Rank test showed high significant differences for rest of the measured parameters between inflow and outflow with $\mathrm{p} \ll 0.05$ as showed in Table 1 .

TABLE 1. TeSt OF DifFERENCES OF WATER QuALiTy PARAMETERS AT THE INFLOW AND OUTFLOW

\begin{tabular}{|c|c|c|c|}
\hline \multicolumn{4}{|c|}{$p$-values for normality (Kolmogorov-Smirnov test) } \\
\hline & $\mathrm{TN}$ & TP & TSS \\
\hline Inflow & 0.3839 & 0.0004 & 0.0002 \\
\hline Outflow & 0.1585 & $<0.00001$ & $<0.00001$ \\
\hline \multicolumn{4}{|c|}{$p$-values for the comparison of concentrations, $\mathrm{mg} \mathrm{L}^{-1}$} \\
\hline Test $p$-values & $<0.00001^{*}$ & $<0.00001^{* *}$ & $0.0001 * *$ \\
\hline
\end{tabular}

\section{Conclusions}

Monitoring data highlighted firstly the water quality from populated agricultural areas, with specific surface runoff from the farmyards. The parameter concentrations observed in this study site of the farm 'Mezaciruli' in Latvia, can be attributed to other local areas as agricultural equipment storage places, animal movement areas, temporary storage of bulk organic materials and other areas with hard surface coverage and potential of organic matter leakage. There are poorly defined regulations for this kind of wastewater. No treatment is strongly required for the storm water from relatively small areas outside the cities and management of the pollution is usually individually solved.

The treatment system with subsurface flow constructed wetland in the study site showed a good treatment efficiency for all monitored water quality parameters during the study period. The nitrogen compound concentrations in forms of $\mathrm{NO}_{3}-\mathrm{N}, \mathrm{NH}_{4}-\mathrm{N}$ and $\mathrm{TN}$ were decreased on average by $21 \%, 64 \%$ and $53 \%$, respectively. However, the reduction was not stable and in some sampling cases the concentrations of nitrogen compounds increased at the outflow. This can be explained with the incomplete denitrification process inside the wetland filter. $\mathrm{PO}_{4}$ $\mathrm{P}$ and TP concentrations were reduced during the treatment process with the average retention of $78 \%$ and $80 \%$, respectively. Cases with the increase of both parameters during the study period were detected.

The treatment efficiency of the constructed wetland for parameters reflecting the content of organic matter in a water showed a high potential in this study. The retention of $\mathrm{BOD}_{5}$ and COD was detected in all study period and the possible dependency on water amount was highlighted.

The results indicate that if constructed wetlands are properly designed and operated, they could be successfully used for wastewater treatment under local conditions.

\section{ACKNOWLEDGEMENT}

This work has been supported by the Latvia University of Life Sciences and Technologies Fund implementation of the research program within the project "The Evaluation of Biochemical and Chemical Oxygen Demand in a Subsurface Flow Constructed Wetland" No. P10. 


\section{REFERENCES}

[1] Rahmadyanti E., Wiyono A., Firmansyah G. A. Integrated system of biofilter and constructed wetland for sustainable batik industry. International Journal of GEOMATE 2020:18(70):138-148. https://doi.org/10.21660/2020.70.61681

[2] Ventura D., et al. On the performance of a pilot hybrid constructed wetland for stormwater recovery in Mediterranean climate. Water Science and Technology 2019:79(6):1051-1059. https://doi.org/10.2166/wst.2019.103

[3] Wang J., et al. A constructed wetland system with aquatic macrophytes for cleaning contaminated runoff/storm water from urban area in Florida. Journal of Environmental Management 2021:280:111794. https://doi.org/10.1016/i.jenvman.2020.111794

[4] Gimenez-Maranges M., et al. The transition to adaptive storm-water management: Learning from existing experiences in Italy and Southern France. Sustainable Cities and Society 2020:55:102061. https://doi.org/10.1016/j.scs.2020.102061

[5] Abed S. N., Almuktar S. A., Scholz M. Phytoremediation performance of floating treatment wetlands with pelletized mine water sludge for synthetic greywater treatment. Journal of Environmental Health Science and Engineering 2019:17(2):581-608. https://doi.org/10.1007/s40201-019-00372-z

[6] Abou-Elela S. I., Fawzy M. E., El-Gendy A. S. Potential of using biological aerated filter as a post treatment for municipal wastewater. Ecological Engineering 2015:84:53-57. https://doi.org/10.1016/j.ecoleng.2015.07.022

[7] Abou-Elela Sohair I., et al. Municipal wastewater treatment in horizontal and vertical flows constructed wetlands. Ecological Engineering 2013:61:460-468. https://doi.org/10.1016/j.ecoleng.2013.10.010

[8] Abou-Elela S. I., Hellal M. S. Municipal wastewater treatment using vertical flow constructed wetlands planted with Canna, Phragmites and Cyprus. Ecological Engineering 2012:47:209-213. https://doi.org/10.1016/j.ecoleng.2012.06.044

[9] Gajewska M., et al. Kinetics of pollutants removal in vertical and horizontal flow constructed wetlands in temperate climate. Science of the Total Environment 2020:718:137371. https://doi.org/10.1016/j.scitotenv.2020.137371

[10] Qasim S. R. Wastewater treatment plants, planning, design and operation. Boca Raton: CRC Press, 2000.

[11] Vymazal J. Constructed Wetlands for Wastewater Treatment: A Review. Proceedings of the 12th World Lake Conference 2008:965-980.

[12] Council Directive 91/676/EEC of 12 December 1991 concerning the protection of waters against pollution caused by nitrates from agricultural sources. Official Journal of the European Communities 1991:L 375.

[13] Crites R. W., et al. Natural Wastewater Treatment Systems. Boca Raton: CRC Press, 2014.

[14] Styes K. R., Zarus G. M., Ryan B. Water Quality Improvements of Constructed Wetland Elements in an Urban Environment. Stormwater 2015.

[15] Lia Y., et al. Evaluation of the long-term performance in a large-scale integrated surface flow constructed wetland-pond system: A case study. Bioresource Technology 2020:309:123310 https://doi.org/10.1016/j.biortech.2020.123310

[16] Akgiray Ö. Explicit solutions of the Manning equation for partially filled circular pipes. Canadian Journal of Civil Engineering 2005:32(3):490-499. https://doi.org/10.1139/L05-001

[17] Saaremäe E., et al. Removing phosphorus with Ca-Fe oxide granules - a possible wetlands filter material. Hydrology Research 2014:45(3):368-378. https://doi.org.10.2166/nh.2013.101

[18] Allen R. G., et al. Crop evapotranspiration - Guidelines for computing crop water requirements. FAO Irrigation and drainage paper 56. Rome: FAO, 1998.

[19] Nifong R. L., Taylor J. M. Vegetation and Residence Time Interact to Influence Metabolism and Net Nutrient Uptake in Experimental Agricultural Drainage Systems. Water 2021:13(10):1416. https://doi.org/10.3390/w13101416 